\title{
Pseudoclitocybe atra (Vel.) n. comb.
}

\author{
Harri Harmaja \\ Botanical Museum, University of Helsinki, SF-00170 Helsinki, Finland
}

\begin{abstract}
Harmaja, H. 1974: Pseudoclitocybe atra (Vel.) n. comb. - Karstenia 14: 126-128. The new combination Pseudoclitocybe atra (Vel.) Harmaja (Agaricales) is made, and the species is described. The species is distinguished through the presence of distinct, fairly abundant dermatocystidia, very simple in structure, which are responsible for the characteristic satiny lusrte of the moist pileus surface, further through the pure dark brown colours (paler in the dried condition) of the fruit body without any greyish tint, the mat surface of the dried pileus, and the fairly long spores. Also certain other though minor differences from the other species of the genus seem to exist. All the specimens were collected in human-influenced sites in the litter of grasses mixed with mull. Apart from the dermatocystidia, several sporal and macrochemical characters are reported for the first time in the genus. The species is new for Finland and Western Germany.
\end{abstract}

Pseudoclitocybe atra (Vel.) Harmaja, n. comb. (Clitocybe atra Velenovský, Novitates mycologicae: 68. 1939. - Holotype examined: Czechoslovakia, Bohemia, »Mnichovice, in silva laricina inter gramina, XII.1934, J. Velenovský»; PR-153496 p.p.). - The specimen, labelled as to contain the types of $C$. atra and $C$. compressa, consists of three basidiocarps, the darkest of which obviously being the type of the former while the two paler ones with compressed stipes represent the latter which is a mere herbarium name (and they belong to $P$. cyathiformis). The spores of $C$. atra were described as globose and 3-4 $\mu \mathrm{m}$ in diameter, but quite obviously this is due to a contamination with abundant small hyaline ellipsoid basidiomycete spores on the gills (Velenovský not infrequently described definitely ellipsoid spores as globose; cf. Harmaja 1970: 36, 37) while the large amyloid Pseudoclitocybe spores were few and collapsed. The clamps were lacking.

Pileus reaching a diameter of $4.5 \mathrm{~cm}$, hygrophanous, not pruinose, rather weakly translucent-striate at margin (in old caps even up to halfway towards centre), when moist chocolate brown (8 E 10; the colours are described in the terms of MAERz \& Paul 1950), usually becoming somewhat paler in age (e.g. 7 A 10), in dried basidiocarps usually somewhat paler than in the fresh condition (e.g. 13 B 7, 14 B 5), infundibuliform already when young, becoming deeply so in age; surface not viscid or slimy, in the moist condition with a distinct satiny lustre when observed from the side (especially in young basidiocarps), when dry mat and with concentrical wrinkles.

Stipe $4.0-6.5 \times 0.3-1.0 \mathrm{~cm}$, more or less concolorous with pileus, also when dry, slightly enlarging downwards, solid, terete; surface not viscid or slimy, with thin fibrillose longitudinally arranged coating; at the base fairly abundant whitish hyphal tomentum and a few slender whitish rhizoids.

Lamellae moderately decurrent, in both moist and dried condition paler than pileus (when moist $11 \mathrm{~B} 5$, when dry $11 \mathrm{C} 4,12$ D 7 or $12 \mathrm{E} 6$ ), arranged in three verticils, usually broadest in the middle, rarely towards the pileus margin, $3-5 \mathrm{~mm}$, in the middle 3 - 5 times broader than overlying context is thick, neither forked nor intervenose. 
Odour faint when fresh but becoming slightly stronger when drying, being somewhat musty or like that of rubber or ink or Peziza badia; dry fruit bodies practically odourless.

Taste mild in both fresh and dried fruit bodies.

Spores (in Melzer's unless otherwise stated) $7.8-11.0(-12.0) \times 4.8-6.0 \mu \mathrm{m}$; a considerable proportion of the detached spores adhere together in tetrads and dyads in mounts of dried gills; a great many of them, especially the young ones mostly still attached to the sterigmata, with strikingly collapsed walls in mounts of dried gills; perhaps most obtuse-based, the rest acute-based; probably most ellipsoid, the rest being ovoid, oblong and obovoid; suprahilar area, or plage, applanated to slightly depressed; wall ca. $0.4 \mu \mathrm{m}$ thick, smooth, hyaline in water and 5\% $\mathrm{KOH}$, amyloid, cyanophobic; hilar appendix ca. $0.9-1.3 \times 0.7-1.2 \mu \mathrm{m}$, tapering towards apex, with an inamyloid and cyanophobic wall; contents moderately cyanophilic, without distinct oil guttules; colour of spore deposit unknown.

Basidia ca. $35-45 \times 7.5-10.0 \mu \mathrm{m}$, fourspored.

Hymenophoral trama of the regular type.

Epicutis weakly differentiated, ca. 50-80 $\mu \mathrm{m}$ thick, differing through the narrower, more tightly running and more pigmented hyphae from the context below it; hyphae almost parallel to somewhat interwoven, filamentous, 3.0-7.0 $\mu \mathrm{m}$ in diameter, gradually getting broader downwards; hyphal walls inamyloid, indextrinoid, cyanophobic; all kinds of pigment location present: epimembranal pigment present as very small, brown encrus- ted granules on the hyphal walls, a very pale brown (intra)membranal pigment also present, some hyphae contain brown intracellular pigment, and yellowish crystals present between hyphae, i.e. intercellular pigment (being not easily observed in revived sections but fairly conspicuous in sections prepared of fresh tissue); clamp connections totally absent; fairly abundant, projecting dermatocystidia present, emerging from the outermost hyphae, varying from very short ones to ca. $40 \mu \mathrm{m}$ long and 2.5-6.0 $\mu \mathrm{m}$ in diameter, being usually curved basally, hyaline, nonseptate, slightly to distinctly tapering towards their rounded tips, and with smooth, inamyloid, indextrinoid and cyanophobic walls (Fig. 1). A distinction between an epicutis and a subcutis hardly possible.

Macrochemical tests (made on parts of faded fresh fruit bodies of the Lohja collection; for the concentrations etc. of the reagents used, consult Singer 1962). - Methol: pileus surface faintly violet in few minutes; stipe surface dark violet immediately; context brownish violet immediately (later dark violet). - Potassium hydroxide: pileus, stipe and context negative. - Ammonia: pileus, stipe and context negative. - Nitric acid: pileus reddish yellow immediately; stipe pale orange immediately. - Phenol: pileus and stipe dark vinaceous red in about two minutes. - Formalin: pileus and stipe dirty vinaceous red in few minutes. - Aniline oil: pileus, stipe, lamellae and context deep vinaceous red immediately (cf. Harmaja 1969: 10-11). - Ferrous sulphate: pileus pale green-grey immediately; stipe negative. Ferric sulphate: as preceding. - Guaiac: pileus and stipe grey-green in few minutes;

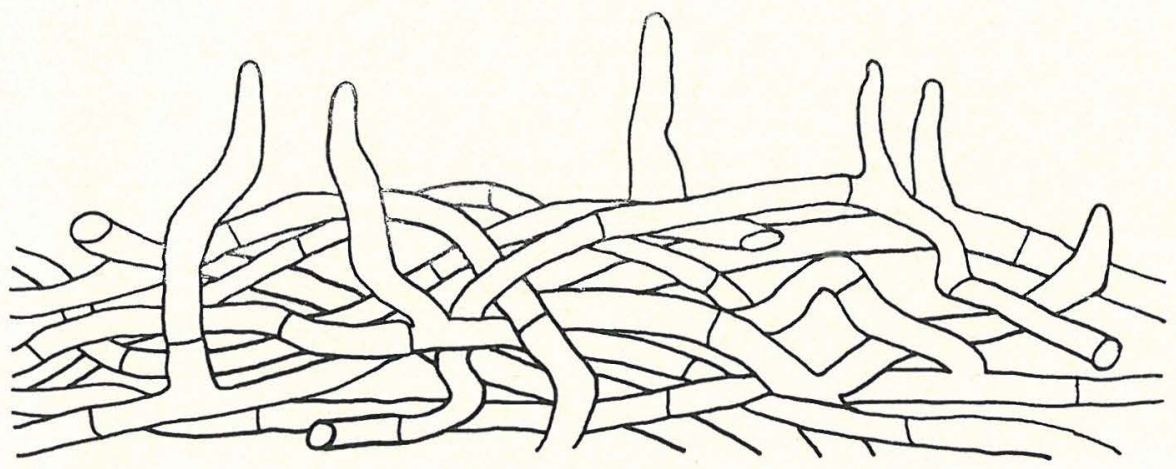

Fig. 1. Pseudoclitocybe atra (Vel.) Harmaja. - Epicutis of pileus with dermatocystidia in $5 \% \mathrm{KOH}$. Pigments omitted. Magnification ca. $1000 \mathrm{x}$. Drawn from the Finnish specimen collected 1965-09-10 in Lohja by the author. 
context bright blue-green immediately.

Ecology. All the specimens were apparently collected in human-influenced sites, in litter of grasses mixed with mull (judging from the debris attached to the bases of the stipes). They were collected from early September to December.

Specimens examined. - Czechoslovakia (type; PR). - Finland: prov. Varsinais-Suomi, rural district of Lohja, Kirkniemi, by the manor, seven fruit bodies on fertile soil at the edge of a ditch in litter consisting of dead culms and leaves of some grass (Gramineae) mixed with mull, the $\mathrm{pH}$ value of this substrate being 5.9 , collected $1965-09-10$ by the author; prov. Pohjois-Savo, rural district of Iisalmi, Kirkkosalmi, Leppiranta, 196509-11, Irja Huuskonen ( $\mathrm{H}$; OULU). Germany (unless Switzerland?): BadenWürttemberg, in a meadow near the town Konstanz (»Auf einer Wiese bei Constanz»), 1861-11-?, J. Kirsner (Wartmann und Schenk: Schweizerische Kryptogamen no. 25, Agaricus cyathiformis Bull. - Herbier Barbey-Boissier no. 2095) (UPS, Herb. E. Fries).

This species is distinguished through the distinct and fairly abundant hairs, or dermatocystidia, arising from the outermost hyphae of the epicutis. Singer (1962) does not mention such elements to be present in the fruit bodies of the species of the genus Pseudoclitocybe, but I have observed occasional, inconspicuous germs, apparently smaller than those of the present species, also emerge from the surface hyphae of some other species of the genus, e.g. P. cyathiformis (Fr.)
Sing. The hairs of $P$. atra seem to be, at least for a considerable part, collapsed in old specimens and difficult to revive, especially if the basidiocarps were pressed; they may also be confused with the hyphae of moulds. Being rather inconspicuous they are most easily observed in sections made of fresh caps, since it is more difficult to cut perpendicularly to the densely wrinkled surface of a dry pileus. The dermatocystidia are no doubt responsible for the rather striking satiny lustre of the pileus surface of moist, especially young carpophores (in which the hairy covering is denser than in old ones), when observed from the side. They can readily be observed even in dried fruit bodies under a dissecting microscope with a magnification of $50 \mathrm{x}$. Further, the pure brown colours without any greyish tinge, the mat surface of the dried pileus, and the fairly long spores with a large hilar appendix are diagnostic of $P$. atra. The flesh of the pileus is very thin, and a distinction between an epicutis and a subcutis in the cortex of the pileus cannot with certainty be made, which characters, too, appear to have taxonomical significance. Whether there are any diagnostic characters in the habitat ecology of this species, e.g. the kind of substrate, remains to be ascertained with a larger material.

The German specimen and that from Iisalmi, Finland, comprise somewhat paler fruit bodies than the rest two ones.

Acknowledgements. - My thanks are due to Prof. Dr. Albert Pilát (PR), Dr. Rolf Santesson (UPS) and Curator Tauno Ulvinen (OULU) for placing valuable specimens of Pseudoclitocybe at my disposal.

\section{REFERENCES}

Harmaja, H. 1969: The genus Clitocybe (Agaricales) in Fennoscandia. - Karstenia 10: $5-168$.

- 1970: Type studies on Agaricales described as Clitocybe and Omphalina. - Karstenia
11: $35-40$.

Maerz, A. and Paul, M. R. 1950: A dictionary of color. -208 pp. New York.

Singer, R. 1962: The Agaricales in modern taxonomy. 2nd ed. - $915+73$. Weinheim. 